\title{
Donuk omuzla başvuran ve meme kanseri tanısı alan bir olgu
}

\author{
A patient presenting with frozen shoulder and diagnosed as breast cancer
}

Feyza ÜNLÜ ÖZKAN, Iş11 ÜSTÜN, Fatma Nur SOYLU BOY, Selin BOZKURT ALP, İlknur AKTAŞ

\section{ÖZET}

Adeziv kapsülit (donuk omuz) şiddetli ağrı ile omuz ekleminin aktif ve pasif hareketlerinde kısıtlılığa neden olan bir sendromdur. Genellikle olay kendini sinırlar ve altta yatan bir neden yoksa aylar içinde spontan olarak geriler. Adeziv kapsülit bir neden olmaksızın idiyopatik olarak ortaya çıkabileceği gibi daha sıklıkla omuz lezyonları sonucu ikincil olarak gelişir. Travma, diyabet, Parkinson, kardiyovasküler, tiroid, akciğer hastalıkları ve malignitelerle birlikte gözlenebilir. Yazımızda, donuk omuzla başvuran ve meme kanseri tanısı alan bir olguyu sunuyoruz.

Elli dört yaşında kadın hasta her iki omuzda ağrı ve hareket kısıtlılığı şikayeti ile polikliniğimize başvurdu. Ağrısı 8 ay önce başlamıştı, travma öyküsü yoktu. İki ay önce omuzun sıkışma sendromu tanısıyla fizik tedavi programına alınmıştı, tedaviden sonra ağrısının azalmadığını, hareket kısıtlılığının arttığını belirtti. Subakromial enjeksiyon testi negatif bulundu. Omuz grafisi normal sınırlardaydı, omuz manyetik resonans görüntüleme (MRG) incelemesinde solda bisipital tendinit saptand1. Hemogram, akut faz reaktanları ve biyokimyasal testler normal sınırlarda bulundu. Hasta sistemik açıdan sorgulandığında fibrokistik meme hastalığı olduğu, kollarını kaldıramadı̆̆ 1 için son mammografi kontrolünü yaptıramadığı öğrenildi. Bunun üzerine hastadan meme MRG'si istendi, sağ memesinde saptanan kitleden yapılan biyopside invaziv duktal meme karsinomu saptandı. Adeziv kapsülitin ayırıcı tanısında maligniteler mutlaka yer almalıdır. Ayrıntılı bir anamnez ve sistemik muayene altta yatan primer patolojinin aydınlatılmasını sağlar.

Anahtar Kelimeler: Adeziv kapsülit, Donuk omuz, Malignite, meme kanseri

Feyza Ünlü Özkan (范), Selin Bozkurt Alp, İlknur Aktaş

Fiziksel Tup ve Rehabilitasyon Kliniği, Fatih Sultan Mehmet Ĕgitim ve

Araştırma Hastanesi, Istanbul, Türkiye

e-mail:feyzamd@yahoo.com

Iş11 Üstün

Fiziksel Tip ve Rehabilitasyon Kliniği, Bağcılar Ĕ̆itim ve Araştırma

Hastanesi, Istanbul, Türkiye

Fatma Nur Soylu Boy

Radyoloji Kliniği, Fatih Sultan Mehmet Eğitim ve Araştırma Hastanesi, İstanbul, Türkiye

Gönderilme/Submitted: 14.04 .2014

Kabul/Accepted: 06.05 .2014

\begin{abstract}
Adhesive capsulitis (frozen shoulder) is characterized by limitation of active and passive shoulder motions and severe pain. It is selflimiting and resolves in months when there is no underlying pathology. Adhesive capsulitis may be idiopathic but usually secondary to shoulder lesions. Diabetes, Parkinsonism, cardiac, thyroid, respiratory diseases and malignancy may coexist. We report a patient presenting with adhesive capsulitis and diagnosed as breast cancer.

A 54-year-old female admitted with bilateral shoulder pain and limitation of motion. The pain began 8 months ago, and the patient had physical therapy which worsened the symptoms. On physical examination, the shoulder range of motions were limited at all planes. Subacromial injection test was negative. Roentgenograms were normal, shoulder magnetic resonance imaging (MRI) revealed bicipital tendinitis on the left. Complete blood count, acute phase reactants and biochemical analyses were normal. Her detailed medical history revealed that she had fibrocystic breast disease and was unable to have the last mammography because of the limitation of the shoulders. Therefore, MRI examination of the breasts was performed and a mass lesion was detected on the right. Biopsy of the lesion revealed invasive ductal carsinoma. Malignancy should always be considered in the differential diagnosis of adhesive capsulitis. Detailed history and systemic evaluation helps to clarif the underlying pathology.
\end{abstract}

Keywords: Adhesive capsulitis, Breast cancer, Frozen shoulder, Malignacy

\section{Giriş}

Omuz ağrısı, bel ve diz ağrısından sonra en sık görülen kas iskelet sistemi patolojisidir [1]. Omuz ağrısının sık görülmesinin en önemli nedenlerinden biri omuz ekleminin insan vücudunun en hareketli ve en karmaşık eklemi olmasıdır. Adeziv kapsülit, şiddetli ağrı ile birlikte tüm planlarda omuz ekleminin aktif ve pasif hareketlerinde kısıtlılığa neden olan bir sendromdur ve donuk omuz olarak da adlandırılır. Prevalansı \%2-5'tir, 40-60 yaş arasında ve 
kadınlarda daha sık görülür [2]. İlk evrede, ağrı belirgindir, gece ağrısı vardır ve hareketlerde kısıtlanma başlar. İkinci evrede, ağr1 azalırken hareket kısıtlılığ 1 artar, omuzun donduğu dönemdir, üçüncü evrede ise, eklem hareketi yavaş ve kademeli bir şekilde düzelir. Olay genellikle kendini sinırlar ve altta yatan bir neden yoksa aylar içinde spontan olarak geriler.

Adeziv kapsülit, bir neden olmaksızın idiyopatik (primer) olarak ortaya çıkabileceği gibi omuz lezyonları sonucunda da gelişebilir. Adeziv kapsülitin etiyolojisinde, travmaya ve dejenerasyona bağlı rotator kılıf lezyonları, suprasinatus tendiniti, subakromial bursit, akromionun morfolojik anormallikleri, bisipital tendinit, gut hastalığ1, enfeksiyonlar, humerus başı kırık ve dislokasyonları, omuz el sendromu, diabetes mellitus, tiroid bezi fonksiyon bozuklukları, hemipleji, Parkinson hastalığı, akciğer hastalıkları, maligniteler ve mastektomi sayılabilir $[2,3]$.

Yazımızda, donuk omuz ile başvuran ve invaziv duktal meme karsinomu tanısı alan bir hastamızı sunmayı ve literatür eşliğinde tartışmayı amaçladık.

\section{Olgu Sunumu}

Elli dört yaşında kadın hasta her iki omuzda ağrı ve hareket kısıtlılığı şikayeti ile polikliniğimize başvurdu. Ağrısı 8 ay önce başlamıştı. Özellikle son 5 aydır ağrısının şiddetlendiğini ifade etti. 2 ay önce omuz sıkışma sendromu tanısıyla bir merkezde fizik tedavi programına alınmıştı, tedaviye yanıt alınmaması üzerine algoloji kliniğinde radyofrekans uygulaması yapıldığı öğrenildi.

Tedaviden sonra ağrısının azalmadığını ve hareket kısıtlılığının belirgin olarak arttığını belirtti. Hastanın özgeçmişinde fibrokistik meme hastalığı dışında özellik yoktu, soygeçmişinde özellik saptanmadı. 30 yıldır 1 paket/ gün sigara öyküsü mevcuttu. Yakın geçmişte veya önceden geçirilmiş omuz travması veya operasyonu öyküsü yoktu. Hastanın fizik muayenesinde, servikal eklem hareketleri açık ve ağrısızdı. Her iki omuz eklem hareketleri kısıtlı ve ağrılıydı. Her iki omuz aktif ve pasif eklem hareket açıklıkları aynı bulundu. Gonyometre ile sağ omuz fleksiyonu $110^{\circ}$, ekstansiyonu $20^{\circ}$, internal rotasyonu $20^{\circ}$, eksternal rotasyonu $40^{\circ}$, abduksiyonu $100^{\circ}$; adduksiyonu $10^{\circ}$; sol omuz fleksiyonu $110^{\circ}$, ekstansiyonu $30^{\circ}$, internal rotasyonu $10^{\circ}$, eksternal rotasyonu $30^{\circ}$, abduksiyonu 100 derece adduksiyonu $15^{\circ}$ olarak ölçüldü. Neer ve Hawkins sıkışma testleri negatif bulundu. Subakromiyal enjeksiyon testi yapıldı ve negatif bulundu. Nörolojik muayenede her iki üst ve alt ekstremite kas gücü ve duyu muayenesi normal bulundu. Derin tendon refleksleri normoaktifti, patolojik refleks saptanmadı. Her iki omuz ön-arka grafisi normal sınırlardaydı. Daha önce çekilmiş olan omuz manyetik rezonans görüntüleme (MRG) incelemesinde sol omuzda bisipital tendinit mevcuttu. Servikal MRG'de intervertebral disklerde evre 2-3 dejeneratif disk hastalığı bulguları ve C4-5 düzeyinde minimal santral posterior protrüzyon mevcuttu.

Laboratuvar tetkikleri istendi; hemogram, sedimentasyon, crp, serum elektrolitleri, karaciğer ve böbrek fonksiyon testleri normal sınırlardaydı. Sigara öyküsü olması nedeniyle istenen akciğer grafisinde lezyon saptanmadı. Hastanın öyküsü derinleştirildiğinde fibrokistik meme hastalığı için düzenli olarak kontrole gittiği ve mamografi çektirildiği ancak son kontrolünde kollarını kaldıramadığı için mamografinin çekilemediği öğrenildi. Hastadan meme MRG ve ultasonografi (USG) istendi. Meme MRG'de sol memede büyüklüğü $9 \mathrm{~mm}$ 'ye, sağ memede büyüklüğü $7 \mathrm{~mm}$ 'ye varan çok sayıda kistler izlendi. Difüzyon serilerde sağ meme üst orta kadranda $15 \times 23 \mathrm{~mm}$ 'lik alanda, hafif k1sıtlılık oluşturan, solid patolojiyi düşündüren bir alan saptandı. USG'de sağ memede aynı alanda saptanan hipoekoik lezyondan yapılan biyopside infiltratif/invaziv duktal karsinom saptanan hasta genel cerrahi tarafından opere edildi ve kemoterapi başlandı.

\section{Tartışma}

Zuckermann, adeziv kapsüliti primer (idiyopatik) ve sekonder olarak ayırmıştır; sekonder nedenleri de intrensek, ekstrensek ve sistemik nedenler olmak üzere üç grupta inceler [4]. Primer ya da diğer adıyla idiyopatik adeziv kapsülit herhangi bir başlatıcı durum olmadan glenohumeral eklemin ağrılı kontraktürü ile ortaya çıkar. Sekonder adeziv kapsülitin intrensek nedenleri arasında rotator manşon sorunlar1, dejeneratif ya da inflamatuar eklem hasar1, instabilite, eklem travması sayılabilir. Sekonder adeziv kapsülitin ekstrensek nedenleri arasında ise servikal radikülopati, göğüs duvarı tümörü, önceden geçirilmiş meme cerrahisi, humerus şaft kırığı, skapulotorasik anomaliler sayılabilir. Adeziv kapsülitte en önemli faktör immobilitedir. Sistemik nedenlere bağlı adeziv kapsülit ise diyabetes mellitus, hipertiroidi, hipotiroidi, hipoadrenalizm, akciğer malignitesi ve kalp hastalıkları gibi sistemik hastalıklarla birlikte görülebilir.

Omuz ağrısı ve hareket kısıtlılığı nedeniyle başvuran ve adeziv kapsülit tanısı alan bir hastanın değerlendirmesinde iyi bir anamnez ve dikkatli bir fizik muayene son derece önemlidir. Omuz ağrısı eklem kaynaklı patolojilerin yanı sıra servikal, torakal ve abdominal bölgeden de köken alabilir. Bu nedenle omuz muayenesinin yanında servikal ve torakal bölge ile abdomen de değerlendirilmelidir [5]. 
Meme kanseri kadınlarda en sık görülen malignitedir [6]. Gelişen tanı yöntemleri, tedavi modaliteleri ve farkındalıkla birlikte bu kansere bağlı mortalite her geçen gün düşmesine rağmen meme kanseri ne yazık ki halen kırklı yaşlardaki kadınlardaki ölüm nedenlerinin başında gelmektedir. Olgumuz fibrokistik meme hastalı̆̆ meme kontrollerini rutin olarak yaptıran bir kişi olmasına rağmen son mamografisini kollarını kaldıramaması nedeniyle çektirememiştir. Tarama testi olarak kullanılan mamografinin teknik olarak yapılamadığ 1 olgularda meme kontrollerinin USG ve MRG gibi başka inceleme yöntemleriyle mutlaka yapılması sağlanmalı ve bu konuda hastalar bilgilendirilmelidir.

Literatürde bazı omuz tümörlerinin yanlışlıkla donuk omuz olarak tanı aldığ 1 bildirilmiştir [7]. Donuk omuz tanısıyla tedavi alıp, tedavi sonrasında tedaviye yanıtsızlık nedeniyle yeniden değerlendirilen hastalar içinde skapulada Ewing sarkomu, humerus ve skapula malign fibröz histiyositomu, glenoid kondrosarkomu, trapez ve supraspinatusta metastatik skuamoz hücreli karsinom tanıs1 alan bir olgu serisi mevcuttur [8].

Omuz ağrisı ve omuzda hareket k1sitlılığ nadiren de olsa omuz kuşağ1 tümörlerinden kaynaklanabilir. Bu tür hastalarda fizik muayenede saptanan yumuşak doku kitlesi ve bu kitlenin karakteristik radyografik değişiklikleriyle tanı konabilir. Fakat omuz kuşağı neoplazilerinin \%10'unda direkt grafi bulgusu yoktur ve bu hastaları idiyopatik donuk omuz hastalarından ayırdetmek zordur [9].

Literatürde sol omuzda ağrı ve hareket kısıtlılığ nedeniyle başvuran ve metastatik meme kanseri tanısı alan 46 yaşında bir kadın hasta bildirilmiştir [10]. 6 yıl önce meme kanseri nedeniyle opere olan, düzenli takiplerini yaptıran ve metastatik hastalık saptanmayan bu olguda ilk olarak omuz ağrısı rotator manşon patolojisi olarak değerlendirilerek medikal tedavi verilmiş. Konservatif tedaviye yanıt alınamaması üzerine omuz enjeksiyonu yapılmış, ancak bizim olgumuzda olduğu gibi enjeksiyon sonrasında da hastanın ağrısında azalma olmamış. Tedavilere yanit vermemesi nedeniyle ileri tetkike gidilen hastada çekilen tüm vücut kemik sintigrafisinde humerus başında metastatik lezyon saptanmış. Omuz ağrısı ile başvuran kadınlarda primer ve metastatik meme kanseri mutlaka akılda bulundurulmalıdır.

Adeziv kapsülitli hastaların ayırıcı tanısında mutlaka akılda bulundurulması gereken diğer bir patoloji de pankoast tümörüdür. Pankoast tümörleri akciğer apeksinde görülen tümörler olup omuz ağrısı ile prezente olabilir.
Brakial pleksus lezyonu, horner sendromu, radiküler ağrı, parestezi ve duyu kaybı görülebilir [11].

Omuz ağrısı ve donuk omuz nedeniyle başvuran hastalarda ayırıcı tanıda maligniteler mutlaka akılda bulundurulmalıdır. Hasta bir bütün olarak değerlendirilmediğinde malignite ya da yansıyan omuz ağrısı nedenleri atlanabilir ve hasta gereksiz girişimsel işlemlere ve cerrahi tedavilere yönlendirilebilir. Sonuç olarak konservatif tedaviye yanit vermeyen donuk omuzlu hastalarda muayene dikkatle tekrarlanmalı, gerekirse ek radyolojik incelemeler yapilarak altta yatan patoloji aydınlatılmaya çalışılmalıdır.

\section{Kaynaklar}

1. Badley EM, Tennant A. Changing profile of joint disorders with age: findings from a postal survey of the population of Calderdale, West Yorkshire, United Kingdom. Ann Rheum Dis 1992;51:366-71.

2. Hsu JE, Anakwenze OA, Warrender WJ, Abboud JA. Current review of adhesive capsulitis. J Shoulder Elbow Surg 2011;20:502-14.

3. Ewald A. Adhesive capsulitis: a review. Am Fam Physician 2011;83:417-22.

4. Zuckerman JD, Rokito A. Frozen shoulder: a consensus definition. J Shoulder Elbow Surg 2011;20:322-5. doi: 10.1016/j.jse.2010.07.008.

5. Sarpel T. Omuz ağrısı. Beyazova M, Kutsal Y, editör. Fiziksel Tıp ve Rehabilitasyon. Ankara: Güneş Kitabevi, 2000:1437-47.

6. Iglehart DJ, Kaelin KM. Disease of the breast. In: Countney M, Townsend JR, editors. Sabiston Textbook of Surgery. 17th ed. Philadelphia: Saunders, 2004:867-928.

7. Sano H, Hatori M, Mineta M, Hosaka M, Itoi E. Tumors masked as frozen shoulders: a retrospective analysis. J Shoulder Elbow Surg 2010;19:262-6. doi: 10.1016/j. jse.2009.05.010.

8. Quan GM, Carr D, Schlicht S, Powell G, Choong PF. Lessons learnt from the painful shoulder; a case series of malignant shoulder girdle tumours misdiagnosed as frozen shoulder. Int Semin Surg Oncol 2005;2:2.

9. Robinson D, Halperin N, Agar G, Alk D, Rami K. Shoulder girdle neoplasms mimicking frozen shoulder syndrome. J Shoulder Elbow Surg 2003;12:451-5. doi: 10.1016/S10582746(03)00092-2

10. Kim SY, Jung MW, Kim JM. The shoulder pain due to metastatik breast cancer-A case report. Korean J Pain 2011;24:119-22. doi: 10.3344/kjp.2011.24.2.119 PMCID: PMC3111561

11. Foroulis CN, Zarogoulidis P, Darwiche K, et al. Superior sulcus (Pancoast) tumors: current evidence on diagnosis and radical treatment. J Thorac Dis 2013;5(Suppl 4):S342-S358. 